Original article

\title{
Characteristics of haze weather in Chongqing, China and its determinants analysis based on automatic monitoring stations
}

\author{
Mingsheng $\mathrm{Li}^{\mathrm{a}}$, Lin Jia ${ }^{\mathrm{b}}$, Fengying Zhang ${ }^{\mathrm{a}}$, Maogui Hu ${ }^{\mathrm{c}, \mathrm{d},{ }^{*}, \text { Yu Shi }}{ }^{\mathrm{a}}$, Xi Chen ${ }^{\mathrm{e}}$ \\ ${ }^{a}$ China National Environmental Monitoring Center, Beijing 100012, China \\ b Beijing Municipal Research Institute of Environmental Protection, Beijing 100037, China \\ ' State Key Laboratory of Resources and Environmental Information System, Institute of Geographic Sciences and Natural Resources Research, Chinese \\ Academy of Sciences, Beijing 100101, China \\ d Jiangsu Center for Collaborative Innovation in Geographical Information Resource Development and Application, Nanjing 210023, China \\ e Chengdu Environmental Monitoring Center, Chengdu 610072, China
}

\section{A R T I C L E I N F O}

\section{Article history:}

Received 1 December 2015

Received in revised form

28 February 2016

Accepted 28 February 2016

Available online 21 March 2016

\section{Keywords:}

Air quality

Chongqing

Haze

Pollutant levels

Visibility

\begin{abstract}
A B S T R A C T
Statistical analyses were carried out on the characteristics of haze weather and their relation with air quality and meteorological factors using data recorded by the national air quality and meteorological monitoring network of Chongqing, China in 2013. The results showed that the hourly occurrence rate of haze in Chongqing was $81.3 \%$ and that $67.2 \%$ of the total number of haze hours was at the level of mild to light haze. Haze was more likely to occur in autumn and winter $(67.2 \%$ of the total number of hours; occurrence rate $97.5 \%$ ) and was more likely to occur between 22:00 and 10:00. Haze mainly occurred when the wind speed was $<1.2 \mathrm{~m} \mathrm{~s}^{-1}$ and the relative humidity was $>50 \%$. Haze rarely occurred when the wind speed was $>3.0 \mathrm{~m} \mathrm{~s}^{-1}$ and the relative humidity was $<30 \%$. There was a positive correlation between temperature and visibility. The occurrence rate was higher with positive variations in the 24-h temperature records. The main factor affecting haze was the level of $\mathrm{PM}_{2.5}$ pollution. Haze mainly occurred when $\rho\left(\mathrm{PM}_{2.5}\right)$ was between 35 and $250 \mu \mathrm{g} \mathrm{m}{ }^{-3}$, accounting for $86.4 \%$ of the total number of hours of haze. When $\rho\left(\mathrm{PM}_{2.5}\right)$ was $>75 \mu \mathrm{g} \mathrm{m}^{-3}$, the occurrence rate of haze was $100.0 \%$. The mean value of $\rho\left(\mathrm{PM}_{2.5}\right) / \rho\left(\mathrm{PM}_{10}\right)$ during the hours of haze was $72.9 \%, 17.7 \%$ higher than that at other times. The number of hours with air pollution accounted for $48.8 \%$ of the total number of hours, far less than the occurrence of haze. When the ambient air quality was excellent or good, haze was present in $65.4 \%$ of hours. We suggest that there are differences between the assessment of air quality and the definition of haze used in China. The relationship between haze and air quality would be better matched if we used the World Meteorological Organization's definition of haze (visibility $<5.0 \mathrm{~km}$ ).
\end{abstract}

Copyright $\odot 2016$ Turkish National Committee for Air Pollution Research and Control. Production and hosting by Elsevier B.V. All rights reserved.

\section{Introduction}

Haze is an atmospheric phenomenon in which dust, smoke and other dry particles obscure the clarity of the sky (China Meteorological Administration, 2010). It has been shown that haze weather reduces visibility and affects road traffic safety

\footnotetext{
* Corresponding author. State Key Laboratory of Resources and Environmental Information System, Institute of Geographic Sciences and Natural Resources Research, Chinese Academy of Sciences, Beijing 100101, China. Tel: +86 10 64889055.

E-mail address: humg@igsnrr.ac.cn (M. Hu).

Peer review under responsibility of Turkish National Committee for Air Pollution Research and Control.
}

(Hassan and Abdel-Aty, 2011). In addition, inhalation of the substances present in haze often causes adverse effects on the respiratory and circulatory systems of the human population ( $\mathrm{Nel}$, 2005), leading to an increased risk of death, high rates of admission to hospital and increased levels of unexpected infant mortality during the weather conditions that contribute to haze (Thach et al., 2010; Ge et al., 2011; Guttikunda and Goel, 2013; Liu et al., 2014; Othman et al., 2014; Gao et al., 2015). The reduction in the number of hours of sunshine caused by haze also affects the growth of crops (Moran et al., 2014). Many studies have been carried out on the haze weather, including the changing trends in the occurrence of haze (Husar et al., 2000; Ghim et al., 2005; Wu et al., 2013; Hand et al., 2014), the temporal and spatial distribution of haze (Wang 
et al., 2006; Wu et al., 2009, 2012; Zhao et al., 2011; Tian et al., 2014), the cause of haze (Sansuddin et al., 2011; Zhi et al., 2014), the source characteristics of the aerosol particles present in haze (Norela et al., 2013; Sun et al., 2013) and the distribution of these particles (Kang et al., 2013; Lin et al., 2014). These studies have mainly focused on process analysis techniques (Cheng et al., 2013; Sun et al., 2013) and the data used were obtained from manual monitoring or satellite. Automatic online monitoring provides continuous data about meteorological conditions and has many advantages for the analysis of long time series of data. However, there have been few published reports on haze weather conditions using automatic monitoring data (Chen et al., 2010).

The Beijing-Tianjin-Hebei region, the Yangtze River Delta area, the Pearl River Delta region and the Sichuan Basin are the four areas in China recognized as having a high incidence of haze (Wu et al., 2009). Much detailed research has been published on haze in the Beijing-Tianjin-Hebei region, the Yangtze River Delta area and the Pearl River Delta region (Wang et al., 2006; Wu et al., 2009, 2012; Zhao et al., 2011; Cheng et al., 2013; Sun et al., 2013; Lin et al., 2014; Tian et al., 2014). However, few studies of haze have been carried out in the Sichuan Basin. The characteristics of the haze phenomenon in the Sichuan Basin are different from other regions as a result of specific geographical, climatic conditions and industrial structure (Dai et al., 2013). A study of the haze phenomenon and the mechanisms involved in haze formation in the Sichuan Basin would therefore enrich related research and help our understanding of regional differences in the production of haze.

Chongqing city is one of the four municipalities directly under the control of the central government of China and is the most important city in the Sichuan Basin. In this work, we used the automatic monitoring data recorded for the meteorological conditions and amount of gaseous pollutants in Chongqing in 2013. The characteristics of the haze phenomena and the factors influencing the formation of haze were analyzed to provide a case study of haze and a scientific basis for the control of haze pollution. As a particular air pollution type, haze is an objective reflection of air pollution to people's sense. However, haze and air pollution have independent judgmental standards. Then it occurred that heavy air pollution days may be judged as no haze phenomena while haze days may be judged as good air quality. Influence of $\mathrm{PM}_{2.5}$ on haze was most focused on in previous studies, while their judgment agreement was rarely concerned. Taking Chongqing city as an example, this study analyzed the relation of haze and air pollution based on the haze characteristics, so as to make the judgment of air quality reach an agreement resulting from haze and air pollution.

\section{Methodology and sources of data}

\subsection{Methodology}

The accepted criteria used for the definition of haze are an hourly/daily visibility of $<10.0 \mathrm{~km}$ and a relative humidity $\leq 90.0 \%$ (China Meteorological Administration, 2010; Wu et al., 2013). The hours/days of haze weather influenced by precipitation, sandstorms and snowstorms are excluded. The precipitation data available from the Chinese meteorological data sharing service network are the daily precipitation; hourly precipitation data are not available. Daily precipitation data were not analyzed for the days with obvious precipitation (daily precipitation $\geq 1.0 \mathrm{~mm}$ ). According to the Chinese national industrial standard of observation and forecasting levels of haze (China Meteorological Administration, 2010), the severity of haze can be divided into four levels based on visibility: severe haze (visibility $<2.0 \mathrm{~km}$ ); moderate haze $(2.0 \mathrm{~km} \leq$ visibility $<3.0 \mathrm{~km}) ;$ mild haze
$(3.0 \mathrm{~km} \leq$ visibility $<5.0 \mathrm{~km}) ;$ and slight haze $(5.0 \mathrm{~km} \leq$ visibility $<10.0 \mathrm{~km})$.

The main basis of air quality assessment in China is the Technical Regulations on Ambient Air Quality Index (AQI) (on trial) (HJ 6332012) (Ministry of Environmental Protection of the People's Republic of China, 2012b). However, because the results of this assessment do not always reflect the changing situation with respect to air quality, the Chinese Environmental Monitoring Center modified the calculation method to give an hourly AQI. The hourly AQI is calculated according to adjusted calculation methods, whereas the daily AQI is calculated according to the original regulations (Ministry of Environmental Protection of the People's Republic of China, 2012b).

The hourly AQI is calculated by the following method: Hourly concentrations of $\mathrm{PM}_{10}, \mathrm{PM}_{2.5}, \mathrm{SO}_{2}, \mathrm{NO}_{2}, \mathrm{CO}$ and $\mathrm{O}_{3}$ are subdivided into seven classes, which correspond to seven AQI classes (Table 1). Air Quality Index for pollution $x\left(\mathrm{AQI}_{\mathrm{X}}\right)$ is calculated by

$\mathrm{AQI}_{x}=\frac{\mathrm{AQI}_{x_{-} \text {up }}-\mathrm{AQI}_{x_{-} \text {low }}}{C_{x_{-} \text {up }}-C_{x_{-} \text {low }}} \times\left(C_{x}-C_{x_{-} \text {low }}\right)+\mathrm{AQI}_{x_{-} \text {low }}$

where $C_{x}$ is the hourly concentration of air pollutant x; $C_{X_{-} u p}$ and $C_{x \_l o w}$ are the upper and lower thresholds of the concentration ranges for the air pollutant $x$, respectively; $\mathrm{AQI}_{x_{-} u p}$ and $\mathrm{AQI}_{x_{-} \text {low }}$ are the $\mathrm{AQI}_{x}$ values corresponding to $C_{x_{-} u p}$ and $C_{x_{-}}$low.

Then, the hourly AQI is calculated by

$\mathrm{AQI}=\max \left(\mathrm{AQI}_{\mathrm{X}}\right) \quad(x=1,2, \ldots, 6)$

The calculation of daily AQI is similar to that of the hourly AQI but with a different classification table (Table 2).

\subsection{Data sources and processing}

In this study, hourly concentrations of six air pollutants $\left(\mathrm{PM}_{10}\right.$, $\mathrm{PM}_{2.5}, \mathrm{SO}_{2}, \mathrm{NO}_{2}, \mathrm{O}_{3}$ and $\mathrm{CO}$ ) and six meteorological factors (visibility, temperature, relative humidity, wind speed, wind direction and air pressure) at Lijia air quality monitoring site $\left(106.6^{\circ} \mathrm{E}, 29.6^{\circ}\right.$ $\mathrm{N}$ ) in Chongqing during 2013 were used. The Lijia air quality monitoring site is a state site from China National Ambient Air Quality Monitoring Network. It is not in the immediate vicinity of traffic intersections or major industrial polluters, and is sufficiently distant from any other emission sources. Thus, the monitoring data reflect the general urban air pollution level and meteorological conditions in Chongqing. Because the national ambient air quality monitoring sites are not equipped with rain gauges, we used precipitation data from the Shapingba meteorological observation station in Chongqing (coordinates: $106.3^{\circ} \mathrm{E}, 29.4^{\circ} \mathrm{N}$ ), part of the Chinese meteorological data sharing service network (http://cdc. cma.gov.cn/home.do) operated by National Meteorological Information Center. Missing data were replaced or supplemented with monitoring data from adjacent sites through an interpolation method. The environment monitoring was implemented according to the related Chinese environmental protection standards (Ministry of Environmental Protection of the People's Republic of China, 2005) and weather data monitoring according to those meteorological standards (China Meteorological Administration, 2007a, 2007b, 2007c, 2007d). The statistical analysis and outliers determination of the sample data were according to the national standards.

China National Environmental Monitoring Center is the official environmental monitoring agency of Ministry of Environmental Protection of The People's Republic of China. National Meteorological Information Center is the official data released agency. The two agencies owed strict and integral data quality control and 
Table 1

Assignment of hourly $\mathrm{AQI}_{\mathrm{x}}$ and air pollution specific hourly concentration.

\begin{tabular}{|c|c|c|c|c|c|c|c|}
\hline $\mathrm{AQI}_{\mathrm{x}}$ value & $\mathrm{PM}_{10}\left(\mu \mathrm{g} \mathrm{m}^{-3}\right)$ & $\mathrm{PM}_{2.5}\left(\mu \mathrm{g} \mathrm{m}^{-3}\right)$ & $\mathrm{SO}_{2}\left(\mu \mathrm{g} \mathrm{m}^{-3}\right)$ & $\mathrm{NO}_{2}\left(\mu \mathrm{g} \mathrm{m}^{-3}\right)$ & $\mathrm{CO}\left(\mathrm{mg} \mathrm{m}^{-3}\right)$ & $\mathrm{O}_{3}\left(\mu \mathrm{g} \mathrm{m}^{-3}\right)$ & Classification \\
\hline $0-50$ & $0-50$ & $0-35$ & $0-150$ & $0-100$ & $0-5.0$ & $0-160$ & Excellent \\
\hline $51-100$ & $51-150$ & $36-75$ & $151-500$ & $101-200$ & $5.1-10$ & $161-200$ & Good \\
\hline $101-150$ & $151-250$ & $76-115$ & $501-650$ & $201-700$ & $10.1-35$ & $201-300$ & Slight pollution \\
\hline $151-200$ & $251-350$ & $116-150$ & $651-800$ & $701-1200$ & $35.1-60$ & $301-400$ & Moderate pollution \\
\hline $201-300$ & $351-420$ & $151-250$ & & $1201-2340$ & $60.1-90$ & $401-800$ & Severe pollution \\
\hline $301-400$ & $421-500$ & $251-350$ & & $2341-3090$ & $90.1-120$ & $801-1000$ & Serious pollution \\
\hline $401-500$ & $501-600$ & $351-500$ & & $3091-3840$ & $120.1-150$ & $1001-1200$ & \\
\hline
\end{tabular}

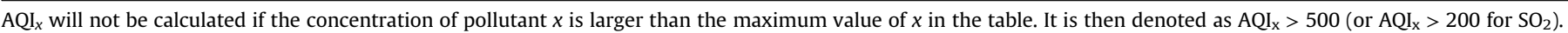

Table 2

Assignment of daily $\mathrm{AQI}_{\mathrm{x}}$ and air pollution specific daily concentration.

\begin{tabular}{|c|c|c|c|c|c|c|c|}
\hline $\mathrm{AQI}_{\mathrm{X}}$ value & $\mathrm{PM}_{10}\left(\mu \mathrm{g} \mathrm{m}^{-3}\right)$ & $\mathrm{PM}_{2.5}\left(\mu \mathrm{g} \mathrm{m}^{-3}\right)$ & $\mathrm{SO}_{2}\left(\mu \mathrm{g} \mathrm{m}^{-3}\right)$ & $\mathrm{NO}_{2}\left(\mu \mathrm{g} \mathrm{m}^{-3}\right)$ & $\mathrm{CO}\left(\mathrm{mg} \mathrm{m}^{-3}\right)$ & $\mathrm{O}_{3}{ }^{\mathrm{a}}\left(\mu \mathrm{g} \mathrm{m}^{-3}\right)$ & Classification \\
\hline $0-50$ & $0-50$ & $0-35$ & $0-50$ & $0-40$ & $0-2$ & $0-100$ & Excellent \\
\hline $51-100$ & $51-150$ & $36-75$ & $51-150$ & $41-80$ & $2.1-4$ & $101-160$ & Good \\
\hline $101-150$ & $151-250$ & $76-115$ & $151-475$ & $81-180$ & $4.1-14$ & $161-215$ & Slight pollution \\
\hline $151-200$ & $251-350$ & $116-150$ & $476-800$ & $181-280$ & $14.1-24$ & $216-265$ & Moderate pollution \\
\hline $201-300$ & $351-420$ & $151-250$ & $801-1600$ & $281-565$ & $24.1-36$ & $266-800$ & Severe pollution \\
\hline $301-400$ & $421-500$ & $251-350$ & $1601-2100$ & $566-750$ & $36.1-48$ & & Serious pollution \\
\hline $401-500$ & $501-600$ & $351-500$ & $2001-2620$ & $751-940$ & $48.1-60$ & & \\
\hline
\end{tabular}

$\mathrm{AQI}_{x}$ will not be calculated if the concentration of pollutant $x$ is larger than the maximum value of $x$ in the table. It is then denoted as AQI $>500$ (or $\mathrm{AQI} \mathrm{I}_{\mathrm{x}}>300$ for $\mathrm{O}_{3}$ ).

a The maximum value of all 8-h moving average concentrations.

quality assurance measures and the released data were the most authoritative.

\section{Results}

\subsection{Statistical analysis of haze weather}

In 2013, the total number of days of haze weather in Chongqing was $301(7224 \mathrm{~h})$, excluding days with precipitation or sandstorms. Haze occurred on 247 days (5872 h) (Fig. 1), i.e. on $82.1 \%$ of the monitored days and $81.3 \%$ of the monitored hours.

Previous data have shown that the frequency of occurrence of haze on non-precipitation days was $21.2 \%$ in Beijing, $15.9 \%$ in Shanghai, 24.7\% in Guangzhou and 57.0\% in Chengdu in 2009 (Dai et al., 2013), 67.2\% in Suzhou between June 2009 and May 2010 (Zheng et al., 2013), and 47\% in Xi'an in 2012 (Kang et al., 2013). The frequency of occurrence of haze in Chongqing in 2013 was therefore higher than in the other cities.

We mainly used hourly data for haze in our analysis because, as a result of statistical ratios, the hourly occurrence frequency of haze (81.3\%) is almost the same as the daily occurrence frequency of haze (82.1\%). Daily data were only used in the analysis of the relationship between haze and the AQI.

Haze occurred in Chongqing in every month of 2013. However, the ratio of the occurrence of haze varied from month to month and plotted as a "U" shape. More than $500 \mathrm{~h}$ of haze occurred between January/March and September/December and the occurrence ratio was $>90.0 \%$. The haze occurred more in winter (December-February) and autumn (September-November) than in summer (June-August). Haze occurred most often and with the highest occurrence ratio in winter. A total of $32.3 \%$ of the annual occurrence of haze was in winter and the ratio of haze occurrence reached $99.9 \%$. The occurrence of haze in autumn was $27.9 \%$ of the annual occurrence of haze and the occurrence ratio was $94.8 \%$. The occurrence of haze in spring $(25.0 \%)$ was similar to that in autumn, but the occurrence ratio (82.6\%) was slightly lower. The lowest occurrence of haze was in summer, although the occurrence ratio was $47.8 \%$.
The haze weather in Chongqing was mainly classified as slight or mild haze, accounting for $37.2 \%$ and $30.0 \%$ of the annual occurrence of haze, respectively. Moderate and severe haze accounted for $19.0 \%$ and $13.8 \%$ of the total, respectively. Severe haze mainly occurred in winter, with an occurrence ratio of $78.5 \%$ of the total hours of severe haze.

Haze occurred least in the afternoon to early evening (13:00-19:00 h) (Fig. 2). Haze frequently occurred from 22:00 to 10:00 h. However, the frequency of occurrence of haze in Chongqing city was $>80.0 \%$. The maximum number of hours of haze was 259 in 9:00, while the minimum number of hours of haze was 226 in 15:00, 16:00 and 17:00. However, the difference is rather small.

In the 301 days of effective monitoring over the whole year, there were only 14 days without any haze. More than $80.0 \%$ of the total days had a visibility of $<10.0 \mathrm{~km}$ for more than half of the day. There were 187 days with 24 h of haze (Table 3 ).

\subsection{Comparison of haze weather and non-haze weather}

Through calculating the meteorological and pollution factors in the hours with and without haze, it was found that there was a significant difference in pollution during haze and non-haze weather. The increase in pollution during haze weather was usually $>30.0 \%$. Among the pollutants measured, $\rho\left(\mathrm{PM}_{10}\right)$ and $\rho\left(\mathrm{PM}_{2.5}\right)$ varied the most and both values increased by more than $100 \%$ during haze weather. $\rho\left(\mathrm{O}_{3}\right)$ was the only factor with an obviously decreased concentration during haze weather. The variations in the meteorological factors such as wind speed, temperature and relative humidity during haze weather were similar to each other (Table 4). Atmospheric pressure only slightly increased during haze weather, showing that it has little effect on the haze phenomena.

\subsection{Analysis of meteorological factors during haze weather}

\subsubsection{Wind velocity and wind vector}

Wind, convection and turbulence are the most direct factors that determine the diffusion of pollutants in the atmosphere. Under certain conditions of atmospheric turbulence, higher wind speeds 


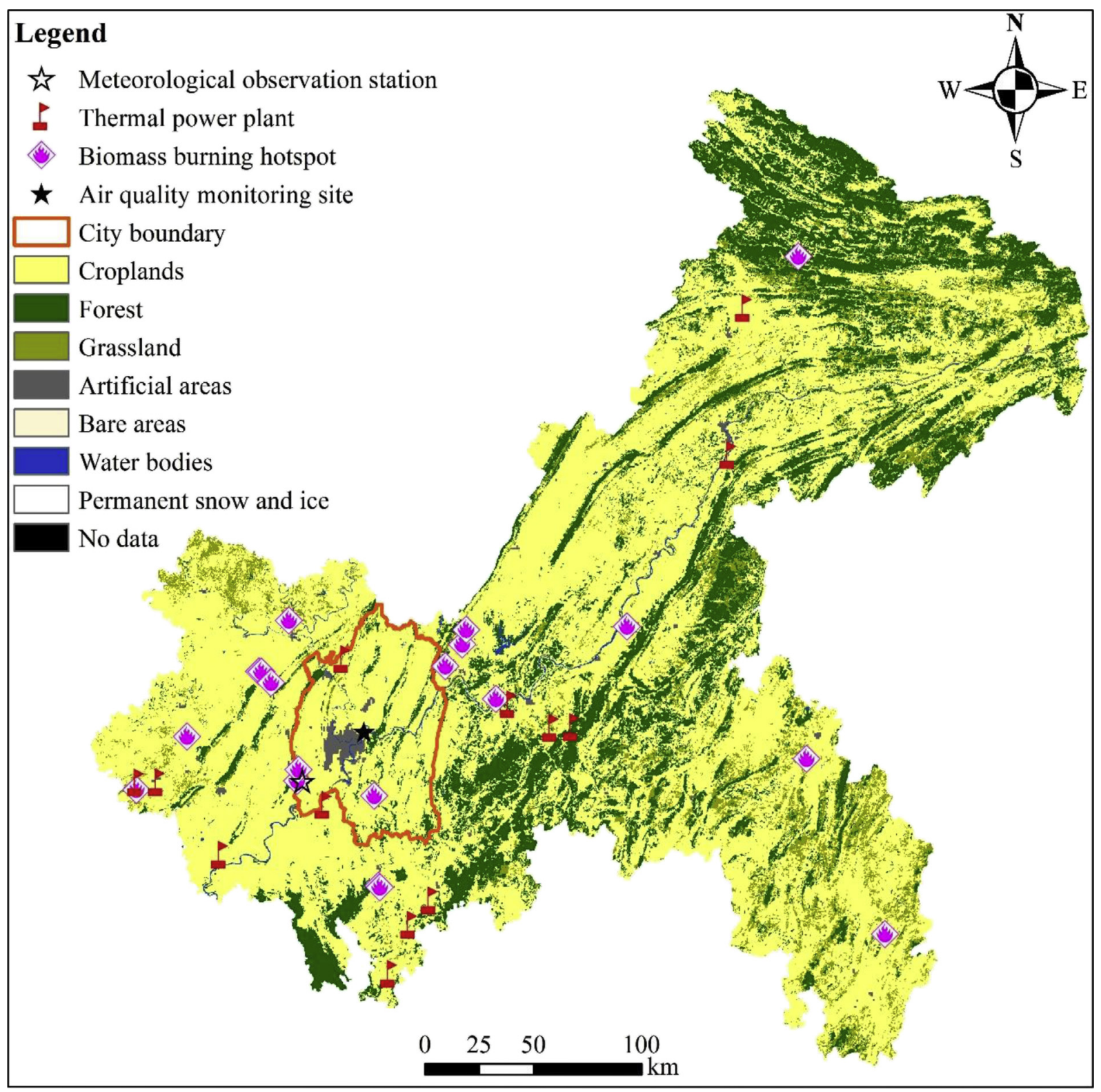

Fig. 1. Land use and distribution of research site in Chongqing.

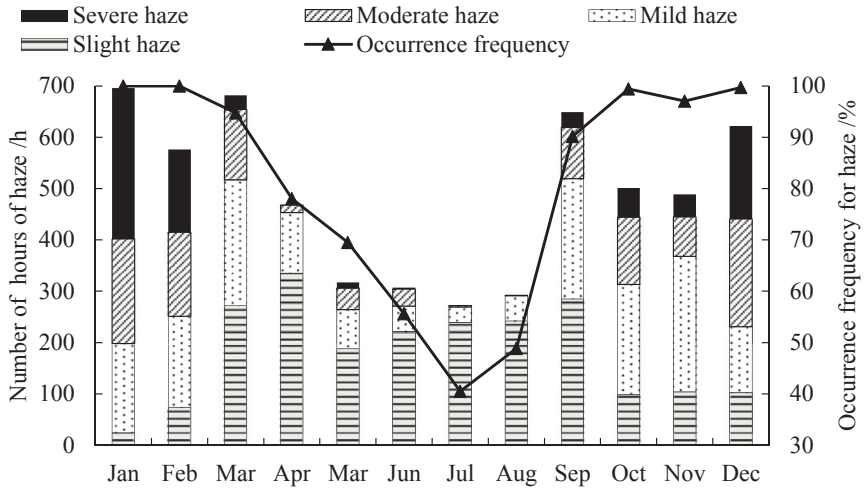

Fig. 2. Monthly data for hours of haze weather and proportion of hours in which haze occurred in Chongqing in 2013.
Table 3

Number of days with different haze hours per day in Chongqing in 2013.

\begin{tabular}{lc}
\hline Number of hours of haze per day/h & Total number of days/d \\
\hline 0 & 14 \\
$1-6$ & 17 \\
$7-12$ & 21 \\
$13-18$ & 31 \\
$19-23$ & 31 \\
24 & 187 \\
\hline
\end{tabular}

are more favorable for the transport and diffusion of atmospheric pollutants. Such conditions are less favorable for the formation of haze. Haze mainly occurred in Chongqing in 2013 when the wind velocity was $<2.0 \mathrm{~m} \mathrm{~s}^{-1}$ and, in particular, when the wind speed was $<1.2 \mathrm{~m} \mathrm{~s}^{-1}$ (Fig. 3); below this wind velocity, the number of hours of haze accounted for $74.4 \%$ of the total. The occurrence ratio for haze showed an obvious negative relationship with wind velocity. The occurrence frequency for haze showed a downwards 
Table 4

Comparison of meteorological indices and concentrations of gaseous pollutants during haze and non-haze weather in Chongqing in 2013.

\begin{tabular}{|c|c|c|c|}
\hline Index & Haze weather $^{\mathrm{a}}$ & Non-haze weather ${ }^{\mathrm{b}}$ & Variation during haze weather $(\%)^{c}$ \\
\hline Visibility $(\mathrm{km})$ & 4.6 & 13.5 & -65.9 \\
\hline Wind speed $\left(\mathrm{m} \mathrm{s}^{-1}\right)$ & 1.0 & 1.5 & -33.3 \\
\hline Temperature $\left({ }^{\circ} \mathrm{C}\right)$ & 18.3 & 29.2 & -37.3 \\
\hline Air pressure $(\mathrm{kPa})$ & 97.2 & 96.3 & 1.0 \\
\hline Relative humidity (\%) & 65.6 & 48.9 & 34.2 \\
\hline$\rho\left(\mathrm{SO}_{2}\right)\left(\mu \mathrm{g} \mathrm{m}^{-3}\right)$ & 36 & 25 & 43.0 \\
\hline$\rho\left(\mathrm{NO}_{2}\right)\left(\mu \mathrm{g} \mathrm{m}^{-3}\right)$ & 49 & 36 & 35.3 \\
\hline$\rho\left(\mathrm{PM}_{10}\right)\left(\mu \mathrm{g} \mathrm{m}^{-3}\right)$ & 129 & 64 & 102.6 \\
\hline$\rho\left(\mathrm{PM}_{2.5}\right)\left(\mu \mathrm{g} \mathrm{m}^{-3}\right)$ & 93 & 38 & 147.6 \\
\hline$\rho(\mathrm{CO})\left(\mu \mathrm{g} \mathrm{m}^{-3}\right)$ & 1.12 & 0.67 & 67.5 \\
\hline$\rho\left(\mathrm{O}_{3}\right)\left(\mu \mathrm{g} \mathrm{m}^{-3}\right)$ & 36 & 82 & -56.6 \\
\hline$\rho\left(\mathrm{PM}_{2.5}\right) / \rho\left(\mathrm{PM}_{10}\right)$ & $72.9 \%$ & $61.7 \%$ & 18.2 \\
\hline
\end{tabular}

Note: $c=(a-b) / b$.

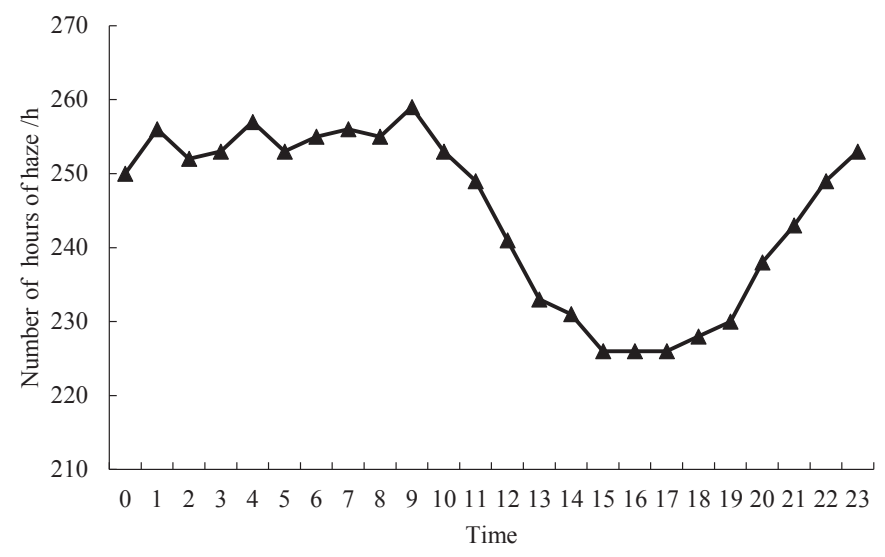

Fig. 3. Total hours of haze for each hour of the day in Chongqing in 2013.

linear trend with increasing wind velocity. Haze almost always occurred when the wind velocity was $<0.3 \mathrm{~m} \mathrm{~s}^{-1}$. The occurrence frequency for haze was $>90.0 \%$ when the wind velocity was $<1.2 \mathrm{~m} \mathrm{~s}^{-1}$ and decreased to $40 \%$ when the wind velocity was $>3.0 \mathrm{~m} \mathrm{~s}^{-1}$. This shows that the wind conditions on the ground are important factors in the formation of haze.

Haze occurred when the dominant wind direction on the ground in Chongqing was to the south, the southeast and south southwest (Fig. 4). The frequency of haze for these three wind directions was $41.1 \%$ of the total number of hours of haze. This is slightly higher than the $39.6 \%$ frequency of wind from these three

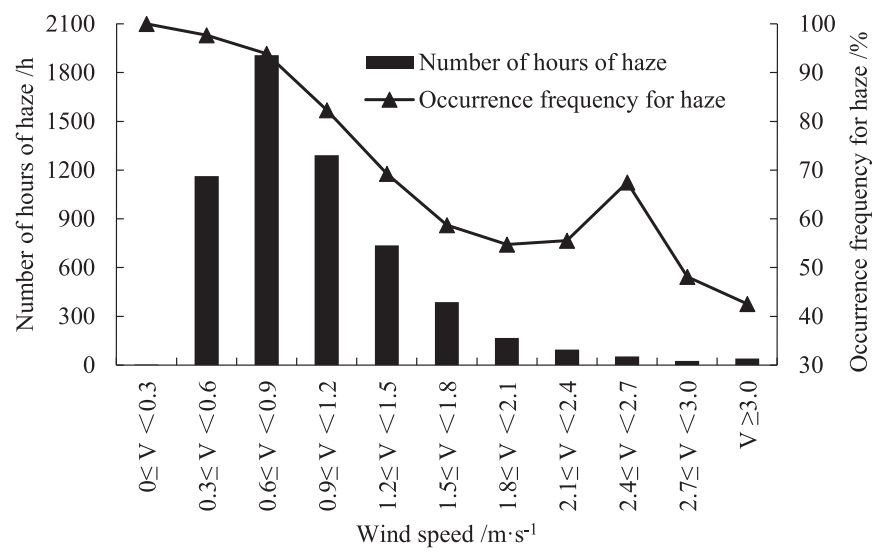

Fig. 4. Number of hours of haze at different wind velocities in Chongqing in 2013. wind directions. The occurrence frequency of severe haze was highest for these three wind directions, with an average of $17.1 \%$ much higher than the average frequency of severe haze (12.2\%).

\subsubsection{Relative humidity}

$\mathrm{PM}_{2.5}$ is the most important factor in haze formation, however, relative humidity also have an effect on haze. Previous studies indicated that moisture absorption of aerosol increased with relative humidity increasing, and then lead to the extinction and scattering ability of the aerosol to increase, and further resulted in the visibility of the atmosphere reducing (Day and Malm, 2001; Malm and Day, 2001; Qu et al., 2015). Otherwise, relative humidity showed positive relation with the aerosol concentration (Howell et al., 2006). Relative humidity increase will further aggravate air pollution, while the aerosol was the most important factor in haze formation. So the higher humidity is conducive to the haze formation. Especially in the heavy fog weather, the impact may be even greater than that from the aerosol particles (Yao et al., 2014). Studies have shown that relative humidity and visibility are negatively correlated, especially when the relative humidity is $>80.0 \%$, and that the visibility decreases in a geometric series (Tian et al., 2014). Our results further support this argument (Table 5). The correlation coefficient for relative humidity and visibility is $-5.4 \times 10^{-1}(p<0.01)$ in Chongqing. When the relative humidity was $<30.0 \%$, less haze occurred; however, when the relative humidity increased to $50.0 \%$, the occurrence frequency of haze increased to about $80.0 \%$. Haze mainly appeared between $50.0 \%$ and $90.0 \%$ relative humidity and this range accounted for $81.2 \%$ of the number of hours of haze.

\subsubsection{Temperature}

Temperature is another important factor affecting visibility. The higher the surface ground temperature, the more dramatic of the air convection and particle's Brown movement. So, the more violent air convection and particle's Brown movement are conducive to atmospheric dispersion and reduction of particulate matter concentration of surface near ground, when the atmosphere temperature is high. When the atmosphere temperature is low, the particulate matter concentration is higher and the visibility is worse, and then it is prone to result in the haze weather (Tsang et al., 1988). The average daily visibility showed a strong positive correlation with the daily maximum and minimum temperatures in Chongqing (Fig. 5). The Spearman rank correlation coefficients of visibility and daily maximum and minimum temperatures were $6.9 \times 10^{-1}$ and $7.0 \times 10^{-1}(p<0.01)$, respectively. The correlation coefficient of visibility and the average daily temperature was $7.1 \times 10^{-1}(p<0.01)$. The correlation between visibility and instantaneous temperature $\left(6.6 \times 10^{-1}\right)$ showed a weak correlation $(p<0.01)$. There is a reciprocal causation relationship between 
Table 5

Haze conditions at different values of relative humidity in Chongqing in 2013.

\begin{tabular}{|c|c|c|c|}
\hline Relative humidity (\%) & Number of hours of haze/h & Number of hours monitored/h & Proportion of hours with haze (\%) \\
\hline $0-10.0$ & 0 & 0 & - \\
\hline $10.1-20.0$ & 2 & 8 & 25.0 \\
\hline $20.1-30.0$ & 54 & 134 & 40.3 \\
\hline $30.1-40.0$ & 345 & 671 & 51.4 \\
\hline $40.1-50.0$ & 703 & 1072 & 65.6 \\
\hline $50.1-60.0$ & 1066 & 1342 & 79.4 \\
\hline $60.1-70.0$ & 1135 & 1297 & 87.5 \\
\hline $70.1-80.0$ & 1252 & 1345 & 93.1 \\
\hline $80.1-90.0$ & 1315 & 1355 & 97.0 \\
\hline
\end{tabular}

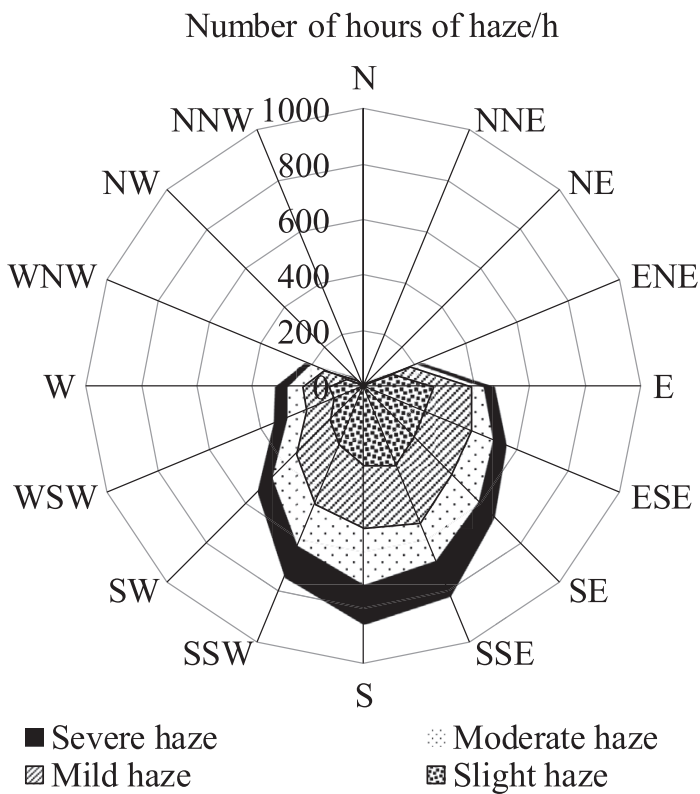

Fig. 5. Number of hours of haze in Chongqing in 2013 during different wind vector.

surface temperature and haze. On one side, haze weather can be easily formed when the temperature is low. On the other side, since haze decrease visibility and solar radiation, it can decrease the temperature (Takemura et al., 2005; Zhang et al., 2010).

To eliminate the influence of seasonal temperature differences on haze, we studied the effect of 24 -h temperature changes on haze (Table 6). In general, positive 24 -h temperature changes often indicate stable synoptic situation. It is beneficial to accumulate the pollution. At the same time, temperature increase in short time can increase the particulate matter's hygroscopicity and decrease the atmospheric visibility, and it then forms haze. On the contrary, negative 24-h temperature changes often mean changes in synoptic situation and there is usually air mass transit. It is conductive to pollution dilution and diffusion, which thereby reducing haze occurrence probability. As a result of the scavenging effect of pollutants, the frequency occurrence of haze was lower when the 24-h temperature changes were negative than when the 24-h temperature changes were positive.

\subsection{Analysis of effect of pollutants on haze}

\subsubsection{Air quality}

Meteorological factors are external causes of the formation of haze weather; air pollutants are internal causes (Wu et al., 2009) and are the material basis of haze formation. Table 7 gives the occurrence of haze and the corresponding air quality grade in Chongqing in 2013. The number of hours of polluted air accounted for $48.8 \%$ of the total number of hours of haze, far less than the proportion for the occurrence of haze $(81.3 \%)$. The occurrence frequency for haze was more than $96.5 \%$ when the air quality reached pollution grade. When the air quality was severe or serious, haze was always present, and severe haze occurred most often. However, when the ambient air quality was excellent or good, haze was still present in $65.4 \%$ of the monitoring hours; $41.2 \%$ of the total number of haze hours was evaluated as having excellent or good air quality.

To quantitatively analyze the relationship between visibility and the AQI, a scatter diagram was plotted using the daily average visibility and the AQI (Fig. 6). The visibility decreased rapidly with a power exponent with increasing values of the AQI. The regression equation of the goodness of fit was $65.1 \%$.

The relation between air quality and visibility was calculated using the regression equation with different degrees of haze. When the visibility was $>10.0 \mathrm{~km}$, the AQI was $<56$ and the air quality was excellent; when the visibility was between 5 and $10 \mathrm{~km}$, the AQI was between 56 and 107 and the air quality was good; and when the visibility was between 3 and $5 \mathrm{~km}$, the AQI was between 107 and 170 and the air quality showed slight to moderate pollution. Thus from the relationship between haze and air quality in Chongqing, the haze judgment standard showed a slightly serious degree of air pollution.

Based on the 2008 criteria of the World Meteorological Organization (World Meteorological Organization, 2008), the significant characteristic of haze is that the visibility is $\leq 5.0 \mathrm{~km}$. Only conditions of mild haze or above were judged as haze according to the standards used in China and the WMO criteria were obviously less stringent than our current standards. According to the WMO standards, the occurrence ratio for haze would decrease from $81.3 \%$ to $51.4 \%$ in Chongqing in 2013. This ratio is closer to the ratio of the air quality pollution (48.8\%) and therefore the relationship between haze and air quality would be better matched.

Table 6

Haze condition in different $\Delta \mathrm{T}_{24}$ in Chongqing in 2013.

\begin{tabular}{|c|c|c|c|}
\hline $24 \mathrm{~h}$ Temperature change $\left({ }^{\circ} \mathrm{C}\right)$ & Number of haze days & Total number of days & Proportion of days with haze (\%) \\
\hline$>0$ & 107 & 120 & 89.2 \\
\hline 0 & 11 & 14 & 78.6 \\
\hline$<0$ & 129 & 167 & 77.2 \\
\hline
\end{tabular}


Table 7

Haze conditions for different grades of air quality in Chongqing in 2013.

\begin{tabular}{|c|c|c|c|c|c|c|}
\hline Air quality grade & No haze (h) & Slight haze $(\mathrm{h})$ & Mild haze (h) & Moderate haze (h) & Severe haze $(\mathrm{h})$ & Proportion of hours with haze (\%) \\
\hline Excellent & 345 & 188 & 67 & 21 & 2 & 44.6 \\
\hline Good & 937 & 1369 & 575 & 148 & 49 & 69.6 \\
\hline Slight pollution & 68 & 581 & 819 & 392 & 111 & 96.5 \\
\hline Moderate pollution & 2 & 40 & 252 & 368 & 119 & 99.7 \\
\hline Severe pollution & 0 & 7 & 47 & 188 & 510 & 100.0 \\
\hline Serious pollution & 0 & 0 & 0 & 0 & 19 & 100.0 \\
\hline
\end{tabular}

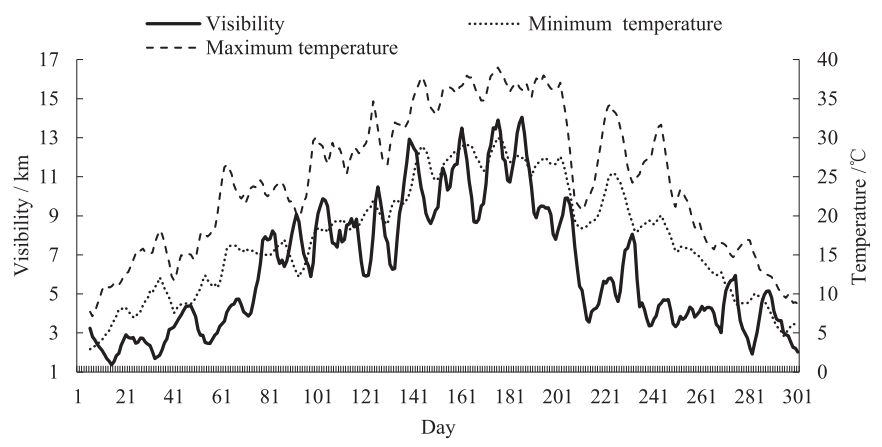

Fig. 6. Trend of daily visibility and minimum and maximum temperatures using a fiveday moving average in Chongqing in 2013.

\subsubsection{Particulate matter}

In our total $5872 \mathrm{~h}$ of haze, $79.4 \%$ of the hours had $\mathrm{PM}_{2.5}$ as the primary pollutant. It implied that the $\mathrm{PM}_{2.5}$ pollution was the most serious, and the multiple exceeding the standard was the greatest. The multiple exceeding the standard equals to the contaminant concentration divided by its standard limit minus one. The hours with $\mathrm{PM}_{10}$ as the primary pollutant accounted for $16.2 \%$ of the total. The hours with both $\mathrm{PM}_{2.5}$ and $\mathrm{PM}_{10}$ as the primary pollutants accounted for $2.0 \%$ of the total number of hours. In total, the hours with particulate matter as the primary pollutant accounted for 97.7\% among hours with haze weather. The correlation coefficient between the hourly visibility and the hourly $\rho\left(\mathrm{PM}_{2.5}\right)$ was $-6.8 \times 10^{-1}$. This is the highest for all the meteorological and pollution factors. The correlation coefficient between the hourly visibility and $\rho\left(\mathrm{PM}_{10}\right)$ was $-6.0 \times 10^{-1}$, which is just less than that between the $\rho\left(\mathrm{PM}_{2.5}\right)$ and relative humidity. Thus particulate matter, especially $\mathrm{PM}_{2.5}$, is the main pollution factor in haze weather.

Through analyzing the distribution of $\mathrm{PM}_{2.5}$ concentrations when haze occurred, we found that haze mainly occurred when

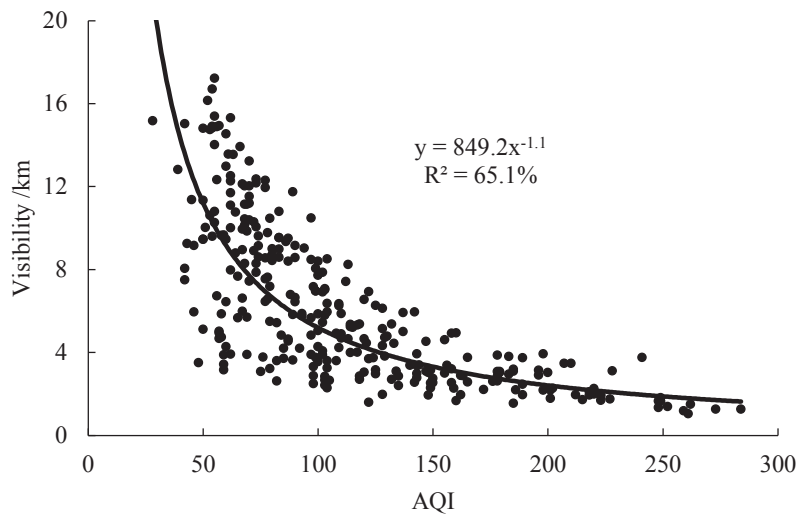

Fig. 7. Scatter diagram for daily visibility and daily AQI in Chongqing in 2013.
$35 \mu \mathrm{g} \mathrm{m}^{-3}<\rho\left(\mathrm{PM}_{2.5}\right)<250 \mu \mathrm{g} \mathrm{m} \mathrm{m}^{-3}$ (Fig. 7). This occurrence accounted for $86.4 \%$ of the total number of hours of haze. The haze occurrence frequency was $100 \%$ when $\rho\left(\mathrm{PM}_{2.5}\right)>75 \mu \mathrm{g} \mathrm{m} \mathrm{m}^{-3}$. Severe haze mainly occurred when $\rho\left(\mathrm{PM}_{2.5}\right)>150 \mu \mathrm{g} \mathrm{m}^{-3}$. The percentage of this occurrence accounted for $63 \%$ of the total occurrence of severe haze. The arithmetic mean of $\rho\left(\mathrm{PM}_{2.5}\right)$ was calculated for haze under different degrees of pollution. $\rho\left(\mathrm{PM}_{2.5}\right)$ increased linearly with the occurrence and aggravation of haze. For mild haze, $\rho\left(\mathrm{PM}_{2.5}\right)$ exceeded the second standard limit of the daily average specified in the Ambient Air Quality Standard (GB 3095-2012) (Ministry of Environmental Protection of the People's Republic of China, 2012a).

Effects of particulate matter on atmospheric extinction coefficient mainly reflect in scattering and adsorption on the visible light of different particle size and components of the aerosol particles. While particles with size $0.25-1.0 \mu \mathrm{m}$ cover the visible wavelength range and contribute most to its scattering efficiency to the visible light and to the extinction coefficient of the visible light. This is why $\mathrm{PM}_{2.5}$ has an important influence on the visibility and haze.

\subsubsection{Ratio of $\rho\left(P M_{2.5}\right)$ and $\rho\left(P M_{10}\right)$}

The average ratio of $\rho\left(\mathrm{PM}_{2.5}\right)$ and $\rho\left(\mathrm{PM}_{10}\right)$ in the air in Chongqing during haze was $70.8 \%$. The ratio during hours of haze was $72.9 \%, 17.7 \%$ higher than in non-haze hours. When the haze was mild or above, the $\rho\left(\mathrm{PM}_{2.5}\right) / \rho\left(\mathrm{PM}_{10}\right)$ was higher than the annual mean. When severe haze occurred, the ratio further increased to 83.1\% and was $33.9 \%$ higher than in non-haze hours (Fig. 8).

The analysis of $\rho\left(\mathrm{PM}_{2.5}\right) / \rho\left(\mathrm{PM}_{10}\right)$ shows that: (1) the mean of the $\rho\left(\mathrm{PM}_{2.5}\right) / \rho\left(\mathrm{PM}_{10}\right)$ ratio for haze hours was $72.9 \%$ and $78.2 \%$ of this ratio was $>60.0 \%$ and that the mean of this ratio in non-haze hours was $61.7 \%$ and only $52.3 \%$ of this ratio was $>60.0 \%$; and (2) the $\rho\left(\mathrm{PM}_{2.5}\right) / \rho\left(\mathrm{PM}_{10}\right)$ ratio increased when $\rho\left(\mathrm{PM}_{2.5}\right)$ increased. The correlation coefficient was $4.2 \times 10^{-1}$ (Figs. 9 and 10).

\section{Discussion}

The frequency of haze occurrence in Chongqing city was relatively higher. The most likely reasons are as follows. (1) The

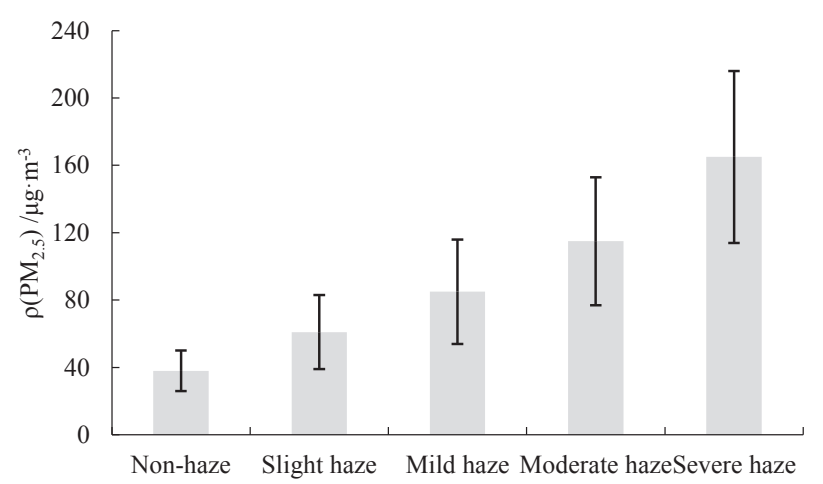

Fig. 8. Concentration of $\mathrm{PM}_{2.5}$ under different levels of haze in Chongqing in 2013. 


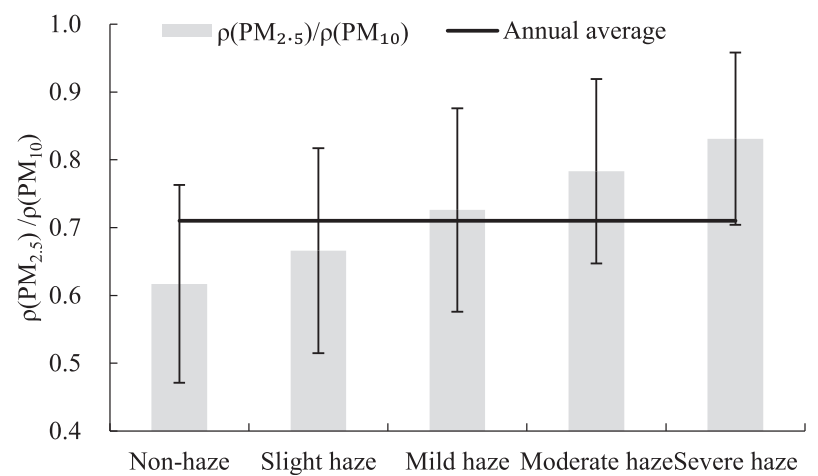

Fig. 9. Concentration ratio of $\mathrm{PM}_{2.5}$ and $\mathrm{PM}_{10}$ under different levels of haze in Chongqing in 2013.
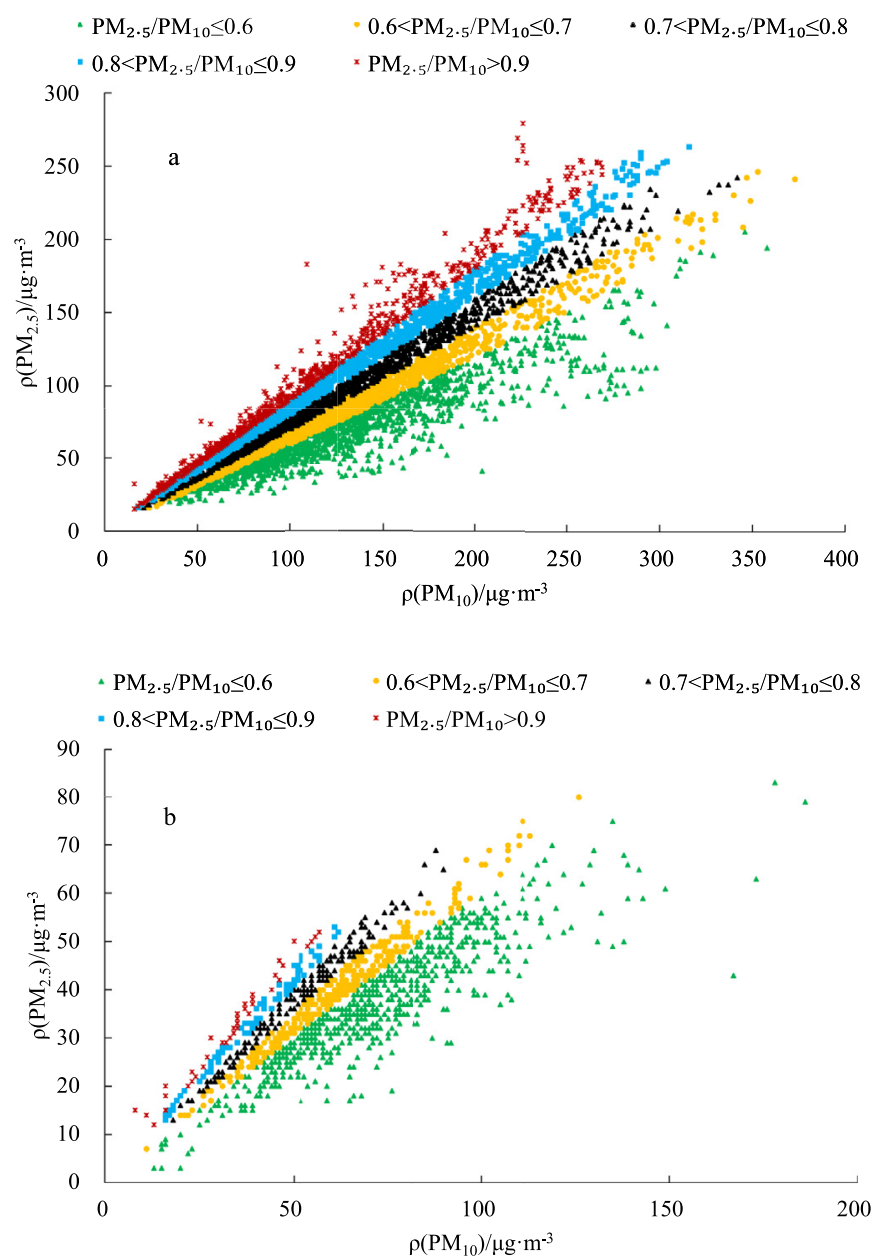

Fig. 10. Scatter diagram for concentration of $\mathrm{PM}_{2.5}$ and $\mathrm{PM}_{10}$ during (a) haze weather and (b) non-haze weather in Chongqing in 2013.

particular climatic conditions of the Sichuan Basin mean that Chongqing is situated in a region more favorable for the formation of haze weather. The Sichuan Basin, where the Chongqing city is located, is the most important industrial base in southwest China. Air pollution is rather heavy there. It is surrounded by mountains with low wind speed and stable atmospheric stratification. It is easy to appear temperature inversion and static wind, which is not conductive to the spread of atmospheric aerosols. So the haze appears frequently in the region. According to the existing research
(Wu et al., 2013), the frequencies of haze occurrence in Chongqing city were just after Shenyang and Xingtai city during 1951-2005. (2) In 2013, haze occurred more frequently due to the extreme deterioration of the national environmental quality. $\mathrm{PM}_{2.5}$ was the major cause of haze weather. Chongqing city began to carry out regular online monitoring of $\mathrm{PM}_{2.5}$ since 2013. The rate of over standards for daily mean of $\mathrm{PM}_{2.5}$ was $47.2 \%$ in Lijia monitoring site in 2013 , while that was just $31.6 \%$ in 2014 . (3) From the time series, the missing data were mainly those in spring and summer. While haze occurred least during the two seasons, thus the missing data would lead to raise the frequency of haze occurrence. The effective sample size of this article was 301 days with 64 days missing due to days of precipitation eliminated and certain period of power off and data without uploading. 48 days $(75.0 \%)$ of the missing days occurred in Month 4-9, while the average occurrence frequency of haze in Month 4-9 was 34.0\% lower than that in the other months. (4) The meteorological conditions in Chongqing in 2013 were favorable for the formation of haze weather. The winter precipitation was $40.0 \%$ below the average and the annual precipitation was similar to that in previous years, although there was a higher frequency of rainstorms. The average temperature was $1.0^{\circ} \mathrm{C}$ higher throughout the year and the weather in spring and summer was the second hottest on record, behind only 2006.

The haze occurrence frequency was higher in our study, but it was not much different compared with previous researches. According the existing research (Wu et al., 2013), the annual haze days remained at about 300 days and thus haze occurrence frequency was $80 \%$ in Chongqing city. The observation results of China Meteorological Bureau showed that haze occurred most in 2013 since 1961 (Ministry of Environmental Protection of the People's Republic of China, 2014).

Stratification of the boundary layer is an important meteorological factor affecting the $\mathrm{PM}_{2.5}$ concentration and further the haze. Mixing layer height is the major factor to explain hourly variation trend (Fig. 2) of haze pollution. But it is a pity that we could only get the publicly released data by the meteorological department, while the meteorological department has not released boundary layer height data, due to a smooth data sharing channels has not been established between Chinese environmental protection departments and the meteorological department.

\section{Conclusions}

1. As a result of its geographical location and particular meteorological and pollution conditions, the occurrence of haze was high in Chongqing in 2013 and the haze occurrence ratio reached $81.3 \%$. Haze occurred most often in winter and autumn, accounting for more than $60.0 \%$ of the frequency of the annual occurrence of haze and the occurrence frequency was $>90.0 \%$.

2. With respect to the haze-related meteorological factors, the visibility had a positive correlation with the wind velocity and temperature and a negative correlation with the relative humidity. Haze appeared in Chongqing when wind velocity was $<1.2 \mathrm{~m} \mathrm{~s}^{-1}$ and the relative humidity was $>50.0 \%$. Haze rarely occurred when the wind velocity was $>3 \mathrm{~m} \mathrm{~s}^{-1}$ and the relative humidity was $>30.0 \%$. When the 24 -h temperature changes were positive, haze occurred more frequently and the visibility and temperature were positively correlated.

3. Particulates, especially $\mathrm{PM}_{2.5}$, are the primary pollution factors in haze. The correlation coefficient of $\mathrm{PM}_{2.5}$ and visibility was the highest of all the meteorological and pollution factors. Haze appeared in Chongqing mainly when $\rho\left(\mathrm{PM}_{2.5}\right)>35 \mu \mathrm{g} \mathrm{m}^{-3}$. The occurrence frequency for haze was $100 \%$ when $\rho\left(\mathrm{PM}_{2.5}\right)>75 \mu \mathrm{g} \mathrm{m}^{-3}$. 
4. The $\rho\left(\mathrm{PM}_{2.5}\right) / \rho\left(\mathrm{PM}_{10}\right)$ ratio increased with increasing haze. The mean of the $\rho\left(\mathrm{PM}_{2.5}\right) / \rho\left(\mathrm{PM}_{10}\right)$ ratio for haze hours was $72.9 \%$ and $78.2 \%$ of this ratio was $>60.0 \%$. The mean ratio in non-haze hours was $61.7 \%$ and only $52.3 \%$ of this ratio was $>0.6$.

5. The results of the air quality evaluation showed an almost positive correlation with the appearance of haze. However, when the air quality was evaluated as excellent or good, $65.4 \%$ hours were still classified as haze. Through the fitting of the curve for visibility and AQI, we found that the visibility was correlated with excellent or good air quality when the visibility was $>5.0 \mathrm{~km}$. Therefore the appearance of haze would be better matched with air quality if the haze standard set by the WMO was used.

\section{Conflicts of interests}

All authors declare they have no conflict of interest to disclose in the context of this study.

\section{Acknowledgments}

This study was partially supported by Ministry of Science and Technology (2012CB955503, 2014ZX07502-002), National Natural Science Foundation of China (41301425). We are grateful to two anonymous reviewers whose comments improved the content of this manuscript. The authors want to thank Dr. Lei Zhou at China National Environmental Monitoring Center for mapping spatial pictures.

\section{References}

China Meteorological Administration, 2007a. Specifications for Surface Meteorological Observation Part 3: Measurement of Meteorological Visibility (QX/T 472007). China Meteorological Press, Beijing (in Chinese).

China Meteorological Administration, 2007b. Specifications for Surface Meteorological Observation Part 6: Measurement of Air Temperature and Humidity (QX) T 50-2007). China Meteorological Press, Beijing (in Chinese).

China Meteorological Administration, 2007c. Specifications for Surface Meteorological Observation Part 7: Measurement of Wind Direction and Wind Speed (QX/T 51-2007). China Meteorological Press, Beijing (in Chinese).

China Meteorological Administration, 2007d. Specifications for Surface Meteorological Observation Part 8: Measurement of Precipitation (QX/T 52-2007). China Meteorological Press, Beijing (in Chinese).

China Meteorological Administration, 2010. Observation and Forecasting Levels of Haze (QX/T 113-2010). China Meteorological Press, Beijing (in Chinese).

Chen, J., Wu, D., Liu, Q.H., 2010. Study of the variation trends of low visibility events in Guangzhou. J. Trop. Meteorol. 26 (2), 156-164 (in Chinese).

Cheng, Z., Wang, S.X., Jiang, J.K., Fu, Q.Y., Chen, C.H., Xu, B.Y., Yu, J., Fu, X., Hao, J., 2013. Long-term trend of haze pollution and impact of particulate matter in the Yangtze River Delta, China. Environ. Pollut. 182, 101-110.

Dai, Y., Tao, J., Lin, Z., Xie, S.D., Cao, J.J., Zhang, R.J., 2013. Characteristics of haze and its impact factors in four megacities in China during 2006-2009. Environ. Sci. 34 (8), 2925-2932 (in Chinese).

Day, D.E., Malm, W.C., 2001. Aerosol light scattering measurements as a function of relative humidity: a comparison between measurements made at three different sites. Atmos. Environ. 35 (30), 5169-5176.

Gao, M., Guttikunda, S.K., Carmichael, G.R., Wang, Y., Liu, Z., Stanier, C.O., Saide, P.E., Yu, M., 2015. Health impacts and economic losses assessment of the 2013 severe haze event in Beijing area. Sci. Total. Environ. 511, 553-561.

Ge, W., Chen, R., Song, W., Kan, H.D., 2011. Daily visibility and hospital admission in Shanghai, China. Biomed. Environ. Sci. 24 (2), 117-121.

Ghim, Y.S., Moon, K.C., Lee, S., Kim, Y.P., 2005. Visibility trends in Korea during the past two decades. J. Air. Waste Manag. Assoc. 55 (1), 73-82.

Guttikunda, S.K., Goel, R., 2013. Health impacts of particulate pollution in a megacity—Delhi, India. Environ. Dev. 6 (1), 8-20.

Hand, J.L., Schichtel, B.A., Malm, W.C., Copeland, S., Molenar, J.V., Frank, N., Pitchford, M., 2014. Widespread reductions in haze across the United States from the early 1990s through 2011. Atmos. Environ. 94, 671-679.

Hassan, H.M., Abdel-Aty, M.A., 2011. Analysis of drivers' behavior under reduced visibility conditions using a structural equation modeling approach. Transp. Res. Part F Traffic Psychol. Behav. 14 (6), 614-625.

Howell, S.G., Clarke, A.D., Shinozuka, Y., Kapustin, V., Mcnaughton, C.S., Huebert, B.J., 2006. Influence of relative humidity upon pollution and dust during ACE-Asia: size distribution and implications for optical properties. J. Geophys. Res. 111 (D6), 925-946.
Husar, R.B., Husar, J.D., Martin, L., 2000. Distribution of continental surface aerosol extinction based on visual range data. Atmos. Environ. 34 (29), 5067-5078.

Kang, E., Han, J., Lee, M., 2013. Chemical characteristics of size-resolved aerosols from Asian dust and haze episode in Seoul Metropolitan City. Atmos. Res. 127, $34-46$.

Lin, Y.F., Huang, K., Zhuang, G.S., Fu, J.S., Wang, Q.Z., Liu, T.N., Deng, C., Fu, Q., 2014 A multi-year evolution of aerosol chemistry impacting visibility and haze formation over an Eastern Asia megacity, Shanghai. Atmos. Environ. 92, 76-86.

Liu, T., Zhang, Y.H., Xu, Y.J., Lin, H.L., Xu, X.J., Luo, Y., Xiao, J., Zeng, W., Zhang, W., Chu, C. et al., 2014. The effects of dust-haze on mortality are modified by seasons and individual characteristics in Guangzhou, China. Environ. Pollut. 187, 116-123.

Malm, W.C., Day, D.E., 2001. Estimates of aerosol species scattering characteristics as a function of relative humidity. Atmos. Environ. 35 (16), 2845-2860.

Ministry of Environmental Protection of the People's Republic of China, 2005. Automated Methods for Ambient Air Quality Monitoring (HJ/T 193-2005). China Environmental Press, Beijing (in Chinese).

Ministry of Environmental Protection of the People's Republic of China, 2012a. Ambient Air Quality Standard (GB 3095-2012). China Environmental Press, Beijing (in Chinese).

Ministry of Environmental Protection of the People's Republic of China, 2012b. Technical Regulations on Ambient Air Quality (AQI) Index (on Trial) (HJ 6332012). China Environmental Press, Beijing (in Chinese).

Ministry of Environmental Protection of the People's Republic of China, 2014 Report on the State of the Environment in China in 2013 (in Chinese).

Moran, R., Bennett, D., Garcia, J., Schenker, M.B., 2014. Occupational exposure to particulate matter from three agricultural crops in California. Int. J. Hyg. Envi ron. Health 217 (2-3), 226-230.

Nel, A., 2005. Air pollution-related illness: effects of particles. Science 308 (5723), 804-806.

Norela, S., Saidah, M.S., Mahmud, S., 2013. Chemical composition of the haze in Malaysia 2005. Atmos. Environ. 77, 1005-1010.

Othman, J., Sahani, M., Mahmudc, M., Ahmad, M., 2014. Transboundary smoke haze pollution in Malaysia: inpatient health impacts and economic valuation. Environ. Pollut. 189, 194-201.

Qu, W.J., Wang, J., Zhang, X.Y., Wang, D., Sheng, L.F., 2015. Influence of relative humidity on aerosol composition: impacts on light extinction and visibility impairment at two sites in coastal area of China. Atmos. Res. 153, 500-511.

Sansuddin, N., Ramli, N., Yahaya, A., Yusof, N., Ghazali, N., Madhoun, W., 2011 Statistical analysis of $\mathrm{PM}_{10}$ concentrations at different locations in Malaysia. Environ. Monit. Assess. 180 (1), 573-588.

Sun, Y., Song, T., Tang, G.Q., Wang, Y.S., 2013. The vertical distribution of $\mathrm{PM}_{2.5}$ and boundary-layer structure during summer haze in Beijing. Atmos. Environ. 74, 413-421.

Takemura, T., Nozawa, T., Emori, S., Nakajima, T.Y., Nakajima, T., 2005. Simulation of climate response to aerosol direct and indirects with aerosol transportradiation model. J. Geophys. Res. 110 (2), 169-190.

Thach, T.Q., Wong, C.M., Chan, K.P., Chau, Y.K., Chung, Y.N., Ou, C.Q., Yang, L., Hedley, A., 2010. Daily visibility and mortality: assessment of health benefits from improved visibility in Hong Kong. Atmos. Res. 110 (6), 617-623.

Tian, S.L., Pan, Y.P., Liu, Z.R., Wen, T.X., Wang, Y.S., 2014. Size-resolved aeroso chemical analysis of extreme haze pollution events during early 2013 in urban Beijing, China. J. Hazard. Mater 279 (30), 452-460.

Tsang, T.T., Pai, P., Korgaonkar, N.V., 1988. Effect of temperature, atmospheric condition, and particle size on extinction in a plume of volatile aerosol dispersed in the atmospheric surface layer. Appl. Opt. 27 (3), 593-598.

Wang, Y., Zhuang, G., Sun, Y., An, Z., 2006. The variation of characteristics and formation mechanisms of aerosols in dust, haze, and clear days in Beijing. Atmos. Environ. 40 (34), 6579-6591.

World Meteorological Organization, 2008. WMO-No. 782-Aerodrome Reports and Forecasts: a User's Handbook to the Codes, fifth ed.

Wu, D., Mao, J., Deng, X., Tie, X., Zhang, Y., Zeng, L., Li, F., Tan, H., Bi, X., Huang, X., et al., 2009. Black carbon aerosols and their radiative properties in the Pearl River Delta region. Sci. China Ser. D 52 (8), 1152-1163.

Wu, D., Lau, A., Leung, Y., Bi, X., Li, F., Tan, H., Liao, B., Chen, H., 2012. Hazy weather formation and visibility deterioration resulted from fine particulate $\left(\mathrm{PM}_{2.5}\right)$ pollutions in Guangdong and Hong Kong. Acta Scien. Circum. 32 (11), 2660-2669 (in Chinese).

Wu, D., Wu, X., Li, F., Tan, H., Chen, J., Chen, H., Chen, H.Z., Cao, Z., Li, H., Sun, X., 2013. Long-term variations of fog and mist in mainland China during 1951-2005. J. Trop. Meteorol. 19 (2), 181-187.

Yao, Q., Cai, Z.Y., Han, S.Q., Liu, A.X., Liu, J.L., 2014. Effects of relative humidity on the aerosol size distribution and visibility in the winter in Tianjin. China Environ. Sci. 34 (3), 596-603 (in Chinese).

Zhang, Y., Wen, X.Y., Jang, C.J., 2010. Simulating chemistry-aerosol-cloud-radiation-climate feedbacks over the continental U.S. using the online-coupled weather research forecasting model with chemistry (WRF/ Chem). Atmos. Environ. 44 (29), 3568-3582.

Zhao, P., Zhang, X., Xu, X., Zhao, X., 2011. Long-term visibility trends and characteristics in the region of Beijing, Tianjin, and Hebei, China. Atmos. Res. 101 (3), $711-718$.

Zheng, Q., Liu, H., Tang, L., Zhu, Y., Zhu, L., Jian, W., 2013. Characteristics of haze in Suzhou. J. Trop. Meteorol. 33 (1), 83-88 (in Chinese).

Zhi, G., Chen, Y., Xue, Z., Meng, F., Cai, J., Sheng, G., Fu, J., 2014. Comparison of elemental and black carbon measurements during normal and heavy haze periods: implications for research. Environ. Monit. Assess. 186 (10), 6097-6106. 